\title{
GOMMENTARY
}

\section{How Can Family Physicians Contribute to Ending Childhood Obesity?}

\author{
Shailen Sutaria, MBBS, MRCGP, MSc; Sonia Saxena, MBBS, MSc, MD
}

(Fam Med. 2019;51(4):308-10.)

doi: 10.22454/FamMed.2019.181036

$\mathbf{P}$ reventing child obesity is seen as the best bet to reverse current trends that predict half the world will be overweight by 2030. Globally, nearly one-third of the world (more than 2.1 billion people) is currently overweight or obese. The World Health Organization (WHO) estimates that 59 million deaths are attributable to high body mass index (BMI). High BMI increases the risk of diabetes 80 -fold, cardiovascular disease by 2.5 times, and reduces productivity through poor health that impacts every organ system. The obesity epidemic is driving up health costs in developed countries. One hundred years ago being overweight was associated with wealth but now rates are highest among the poorest in the population.

The WHO Commission Report on Ending Child Obesity makes five high-level recommendations. ${ }^{1}$ These include (1) improving the environment in which children live, play and learn, (2) supporting healthy food environments such as promoting breastfeeding in early years, (3) making physical activity safe and accessible, and (4) better monitoring of health behaviors and growth of children. The last of these is to work towards achieving universal health coverage to ensure children, adolescents, and their families have access to the obesity prevention and treatment services they need. The first four of these five pillars suggest that the solutions lie in public health measures such as nudge approaches to encourage healthier diet through taxation or education. The fifth points to individual approaches starting with physician acknowledgement, and can play a huge role in addressing weight problems, particularly when health education occurs at a "teachable moment" for those most in need. We examine how family physicians can play a role in both population and individual approaches.

\section{Missed Opportunities to Address Weight Problems in the Consulting Room}

Health systems of many developed countries such as the United Kingdom have achieved many health gains through universal coverage. Almost every child in the United Kingdom is registered with a family physician who offers preventive primary care from birth, with freely-available opportunities to offer health promotion to parents from early years through to adulthood. Similarly, in the United States growth monitoring and early identification of emergent weight problems should occur in the first 2 years of life through well-child care. It is clear however, that in health systems such as the United Kingdom and United States, opportunities to address and prevent weight problems are routinely being missed both inside and outside the consulting room. ${ }^{2}$ A study in the United States suggested family physicians regularly failed to acknowledge weight problems in over half of consultations with adult patients who had a weight-related comorbid condition, yet when they did counsel them, patients were much more motivated to change health behaviors and have a greater awareness of health risks. ${ }^{2}$

From the Child Health Unit, Department of Primary Care and Public Health, Imperial College London, London, UK. 
There is a myriad of reasons why family physicians may overlook opportunities to encourage families to address child obesity. Given the escalating pressures and increasing demand of acute health problems coupled with limited resources, it is not surprising that many physicians prioritize presenting problems over health promotion. Many physicians are reluctant to open a conversation that risks causing offense or can prolong consultation time. Others may lack confidence in their selfefficacy in dealing with weight problems, believe their efforts to be futile in the presence of an obesogenic environment, or cite the lack of high-quality randomized controlled trials (RCTs) of effective interventions in primary care settings that show sustained impact. ${ }^{3}$ A developing evidence base suggests that to be effective, weight loss interventions have to be intensive, with 10 or more encounters, be multicomponent, and involve regular weight monitoring or onward referral to weight management services, the availability of which may vary across regions. An increasing emphasis on policy approaches such as control of advertising, promotion of breastfeeding, taxation, and in-store marketing of sugar sweetened beverages to children may also shift responsibility away from family physicians and individuals. ${ }^{4}$ Despite these challenges, family physicians can play a significant role in addressing child obesity, both through individual treatment plans and population interventions.

\section{How Can Physicians Help Prevent Child Obesity? Individual Approaches}

Family physicians often establish relationships with families through repeated contacts during key stages from preconception, antenatal and postnatal periods, to early years and beyond. These contacts signify early opportunities to educate parents about obesity prevention and provide tailored information.

Routine visits of parents and children could involve some measure of weight and assessment of lifestyle to identify high-risk families and provide specific advice and goals. ${ }^{5}$ Online resources can be used to develop confidence in assessing weight and providing advice on behavior change to families. ${ }^{6}$ The National Child Measurement Programme in England measures the height and weight of children in state primary schools at ages 4 to 5 years and 10 to 11 years. Written feedback is provided to parents about their child's weight status. However, parents of overweight children rarely consult family physicians even when they learn their child has a weight problem. ${ }^{7}$ Integrating routine monitoring of weight in schools with feedback and follow up in primary care may give rise to opportunities to discuss weight and lifestyle, which may be better received when coming from a familiar and trusted source. The identification of an overweight child should prompt family physicians to start a conversation with parents. Family physicians should be aware that parents often do not recognize that their child is overweight and even if they do, may be unaware of the health risks. ${ }^{8}$ Therefore helping parents to understand and accept that their child is overweight, and recognize the health implications for their child is the first step. Excess weight often clusters in families, thus interventions that tackle behavior change for the whole family with intensive psychological and dietician support have the greatest impact.

Amsterdam, one of the few cities that has begun to buck the trend of increasing childhood obesity rates, has done so through a broad range of targeted and integrated social interventions, political leadership, and fully utilizing its primary care services. ${ }^{9}$ It is this established framework of universal coverage, integrated community links, and easy access that has provided a consistent and proactive approach in addressing childhood obesity. Trained and engaged family physicians play an active role in preventing long-term obesity through the early detection and monitoring of high-risk families, provision of timely nutritional advice at various key points through the life course, and links and referrals to community-based intervention programs.

Opening a nonjudgemental conversation about obesity, particularly when the recipient is unaware there may be a problem, requires tact and skill. Motivational and coaching approaches may be more effective for changing health behavior than direct approaches of "telling it like it is." However, physicians need to be given adequate training both to gain confidence in assessing and communicating weight issues to patients and families, and to gain techniques for promoting behavior change and nutritional education. This training must start from an early stage in medical education and continue throughout their residency. 


\section{How Can Family Physicians Contribute to Tackling Child Obesity Through Population Approaches?}

Outside the consulting room, family physicians can play a role as community leaders and model healthy behaviors. According to the 2007 Physicians Health Study, 40\% of the 19,000 doctors surveyed in the United States were overweight and $23 \%$ were obese..$^{10}$ Health professional behavior and weight may influence the acceptability of health advice to families and may affect the physician's willingness to offer advice on health behavior. ${ }^{11}$ Such patterns have been described in studies comparing smoking and nonsmoking physicians in their willingness to discuss smoking and helping patients to quit. ${ }^{12}$ Further lessons can be learned from efforts to reduce smoking prevalence and the role of health professionals. In $1951,87 \%$ of British physicians smoked. Smoking was advertised in medical journals and doctors were used to support prosmoking advertisements. The early debates on the harms of smoking were dismissed by health professionals, the majority of whom smoked. As evidence mounted and health care professionals were confronted with the harms of smoking, prevalence of smoking among health care professionals fell. Health care professionals became engaged in the fight against tobacco, denormalising its use and advocating for its control with support from the public. Now, in the face of increasing evidence on the lifelong harms of childhood obesity, family physicians must use their voice and considerable influence as community leaders to advocate for local and national policies that can alter the obesogenic landscape.

Family physicians must not let disillusionment lead to disengagement and inaction, recalling that turning the tide against smoking was once thought impossible. Neither public health approaches nor individual treatment alone will end child obesity. Family physicians can play a role in both approaches but must be willing to address weight both inside and outside the consulting room.

CORRESPONDENCE: Address correspondence to Dr Shailen Sutaria, Child Health Unit, Department of Primary Care and Public Health, Imperial College London, St Dunstan's Road, London W6 8RP, United Kingdom. shailen000@yahoo.co.uk.

\section{References}

1. World Health Organization. Report of the Commission on Ending Childhood Obesity. Geneva: World Health Organization; 2016. http://apps.who.int/iris/bitstream/handle/10665/204176/9789241510066_eng.pdf;jsessionid=FE23 63CC3F74C31D4218BB0853C2B418? sequence=1. Accessed February 1, 2019.

2. Post RE, Mainous AG III, Gregorie SH, Knoll ME, Diaz VA, Saxena SK. The influence of physician acknowledgment of patients' weight status on patient perceptions of overweight and obesity in the United States. Arch Intern Med. 2011;171(4):316-321.

3. Seburg EM, Olson-Bullis BA, Bredeson DM, Hayes MG, Sherwood NE. A Review of Primary Care-Based Childhood Obesity Prevention and Treatment Interventions. Curr Obes Rep. 2015;4(2):157-173.

4. Lobstein T, Jackson-Leach R, Moodie ML, et al. Child and adolescent obesity: part of a bigger picture. Lancet. 2015;385(9986):2510-2520.

5. McKee MD, Deen D, Maher S, Fletcher J, Fornari A, Blank AE. Implementation of a pilot primary care lifestyle change intervention for families of pre-school children: lessons learned. Patient Educ Couns. 2010;79(3):299-305.

6. Perrin EM, Vann JC, Lazorick S, et al. Bolstering confidence in obesity prevention and treatment counseling for resident and community pediatricians. Patient Educ Couns. 2008;73(2):179-185.

7. Falconer CL, Park MH, Croker H, et al. The benefits and harms of providing parents with weight feedback as part of the national child measurement programme: a prospective cohort study. BMC Public Health. 2014;14(1):549-49.

8. Park MH, Falconer CL, Saxena S, et al. Perceptions of health risk among parents of overweight children: a cross-sectional study within a cohort. Prev Med. 2013;57(1):55-59. .

9. Gemeente Amsterdam. Amsterdam Healthy Weight Programme. https://www.amsterdam.nl/bestuur-organisatie/ organisatie/sociaal/onderwijs-jeugd-zorg/blijven-wij-gezond/ amsterdam-healthy/. Accessed February 1, 2019

10. Kyle RG, Wills J, Mahoney C, Hoyle L, Kelly M, Atherton IM. Obesity prevalence among healthcare professionals in England: a cross-sectional study using the Health Survey for England. BMJ Open. 2017;7(12):e018498.

11. Fie S, Norman IJ, While AE. The relationship between physicians' and nurses' personal physical activity habits and their health-promotion practice: A systematic review. Health Educ J. 2013;72(1):102-119.

12. Pipe A, Sorensen M, Reid R. Physician smoking status, attitudes toward smoking, and cessation advice to patients: an international survey. Patient Educ Couns. 2009;74(1):118123. 